\title{
Stock Verification: Some Problems of Electronic Publications
}

\begin{abstract}
A.K. Dhiman
Abstract

This paper discusses the problems that may be faced by a library professional in stock verification of electronic publications at present or in near future. The main emphasis is given towards the stock verification of compact disks (CDs), today's much used media.
\end{abstract}

\section{INTRODUCTION}

In olden days, the books in libraries were kept locked in almirahs and they were preserved and not issued; consequently the chances of their loss were very few. With the advancement of time and library movement, the concept of keeping the books/documents locked was changed; the documents were kept unlocked in the library to make them available to the readers. But this open access system has led to some problems, such as misplacement and mutilation of books, disturbed order of the books on the shelves and theft of the books and other reading materials in the library. So, it became necessary to prepare an inventory of books/reading materials in the library. Thus, stock verification came into existence for libraries.

\section{STOCK VERIFICATION}

The term stock verification is also denoted by other terms as 'stock taking', 'stock checking', 'stock inspection', 'inventory taking', etc. The term stock verification refers to the process of checking as to what is in stock in relation to what there was. The emphasis is being put more on finding which items are missing than on how much is the loss calculated in rupees. In library context, it is the periodic verification of books and other reading materials of the library. It may be an insignificant aspect of librarianship as far as teachers, researchers and library experts are concerned. But in practice, stock verification is considered a sensitive, controversial and unwanted activity. Practising librarians are often worried over the process of library stock verification and its results and implications.

\subsection{Advantages of Stock Verification}

In spite of its limitations, it has some advantages mentioned as follows:

$O$ Periodic stock verification and writing off of resultant loss helps to reduce unnecessary escalation in the value of assets.

$O$ It helps in replacing relevant, useful and on demand documents with new copies wherever loss or mutilation occurred.

O It helps in reviewing the precautionary measures already taken in preventing loss and mutilation.

O Libraries can find deficiencies in the existing procedure of vigilance and maintenance of library.

It also provides an opportunity for its users to browse the entire collection after verification.

Generally, the reading material in most of the libraries is referred to the books or printed 
material. But, due to advancement of information technology (IT), the physical media of publications has shifted from printed books to the field of non-book/non-printed material. The more popular form of publishing is electronic publishing which is the application of a computer-aided process by which publishers find, capture, shape, store, and update information to disseminate it to a chosen audience (Kist, 1989). The electronic publishing (EP) can be represented as:

$E P$ = Electronic Technology + Computer Technology + Communication Technology + Publishing.

According to Koganuramath et al. (2000), Project Gutenberg, perhaps the best known publisher of book length electronic texts, began in 1971 with the goal of encouraging unlimited distribution of 10000 electronic texts by the end of 2001. It is felt that the Internet is not a satisfactory platform for publishing full text of documents, but Compact Disk-Read Only Memory (CD-ROM) is an appropriate medium for publishing the documents. Books are also available on floppy disks, CDs and Digital Versatile Disks (DVDs, which look alike CDs but have a very large storing capacity of about 17 CB for double-sided version), although distribution by floppy disk is decreasing due to the convenience and growing popularity of CD-ROM.

\section{PROBLEMS WITH ELECTRONIC PUBLICATIONS FACED BY LIBRARIES}

The CDs are acquired in the libraries through two processes. First, the CDs which come free along with the printed material. These are common in case of computer science books. Second, the CDs which libraries subscribe against a payment, as in the case of journals on CDs. For example, CDs of Library \& Information Science Abstract (LISA) in the field of library \& information science and Medicinal \& Aromatic Plant Abstracts (MAPA) in the field of plant sciences.

The following problems are faced by the libraries regarding the stock verification of these electronic publications:

\subsection{Issue/Return of CDs}

The question arises whether the CDs should be issued or not? If yes, then what should be the criteria to follow? The CDs coming free are to be treated as a part of book or separate entity and for how much time these should be issued? If these are considered a free entity and readers do not return, or CDs get non-operational, can these be ultimately treated as written-off material?

\subsection{Life of CDs}

The second question is related to the life of CDs. In the case of books or other printed material, the librarians can just read and use them even after 50 years of its publication. But, as the manufacturers of CDs claim, the life of $\mathrm{CDs}$ is $12-14$ years which in practice could be determined as only 2-2.5 years. Moreover, the $C D$ can get non-operational very soon if mishandled which does not happen at all in the case of printed documents. Are we in a position to weed out a CD costing 1 lakh or more just after 1 or 2 months or immediately after acquiring it for the library.

\subsection{Checking out CD's Content}

If CDs are allowed to take out from the library by the users as printed material, one needs to check its content again when it is returned to the library. It is observed that many libraries do not have necessary computer facilities to check the viability of CDs operation as to whether these have not been spoiled by the users? Even if the computer infrastructure is there, how much trained staff is available in the library for sparing time to check and verify the contents of these CDs? Moreover, in many cases, the libraries are just running single handed by the clerical staff who is generally not aware of technical problems.

\subsection{Criteria of Use}

Generally, in the case of printed material, a loss of 3 books per 1000 consulted or issued books to the readers is permissible and is well within the limit of a librarian, under the approval of competent authority to write off the same. But what will be the criteria to determine the loss factor for CDs? -the number of uses of 
CDs, whether 1000 times actual use in library or merely just handling it 1000 times in the library?

\subsection{Responsibility of Maintenance}

Who can be held responsible in case of mishandling of CDs-librarian or the staff actually handling the CDs in the library? Again, if the staff or librarian is held responsible it will demoralize them and ultimately will affect the library services.

These are some of the problems which the library professionals may face while working in the library presently and in future. We should think seriously for the solutions and then only, we will be able to provide better services to our readers and run the library working smoothly in electronic era of IT.

\section{BIBLIOGRAPHY}

1. Gupta, S.R. Stock Verification in Libraries: Problems and Solutions. Ken Publications, Delhi, 1990.

2. Kist, J. Electronic Publishing. In International Encyclopaedia of Educational Technology, edited by M. Eraut. Pergamon Press, New York, 1989, pp. 600-08.

3. Kogannurmath, M.M.; lange, S. \& Angadi, M. Electronic Publishing: An Analytical Study. In Vision of Future Library and Information System, edited by Babu, et al. Viva Books Pvt. Ltd., New Delhi, 2000, pp. 209-15.

4. Kumbar, M. Stock Verification and Loss of Books in College Libraries: A Survey. Annals Lib Sc Doc, 2000, 47(2), 67-73.

5. Sridhar, M.S. Library Stock Verification: A Ritual and Occupational Hazard. IASLIC Bulletin, 1991, 36(3), 103-10. 